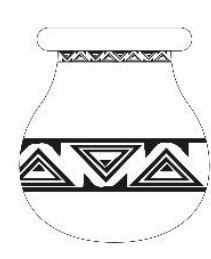

\title{
ADORNO LEITOR DE FREUD: UM DIÁLOGO SOBRE A PSICOLOGIA DAS MASSAS
}

\author{
Mateus Abreu Pereira ${ }^{1}$ \\ Mauricio Rodrigues de Souza ${ }^{2}$
}

Resumo: Já em 1921, Freud inaugurou uma abordagem que considera a psicologia das massas como extensão das experiências individuais, célebre pela afirmação de que toda psicologia é, em última análise, social. Tal perspectiva seria reapropriada por Adorno, que desdobrou a posição freudiana ao situar as massas como um agente decisivo a partir do estágio industrial do capitalismo. Diante do valor deste diálogo, o presente trabalho adotou como objetivo uma análise da reapropriação feita por Adorno da psicologia das massas tal como preconizada por Freud. Mediante uma obrigatória referência a Psicologia das Massas e Análise do $E u$, de Freud, delineou a trajetória do conceito de massa ao longo da obra de Adorno até a culminância de uma psicologia social analiticamente orientada. Em termos conclusivos, aposta que as condições que levam o indivíduo a "ser" massa são relativas à objetividade social que promove a irracionalidade mediante a mercantilização e reificação das relações sociais.

Palavras-chave: Psicologia Social, Psicologia das Massas, Teoria Crítica da Sociedade.

\begin{abstract}
In 1921, Freud inaugurates an approach that considers the group psychology na extension of the individual experiences, notably for his affirmation that all psychology is, in the last analysis, social. Such perspective would be reappropriated by Adorno, who unfolded the Freudian position by situating the masses as a decisive agent from the industrial stage of capitalism. Given the value of this dialogue, the present work adopted as an objective na analysis of the reappropriation made by Adorno of the group psychology as recommended by Freud. Through a mandatory reference to the Group Psychology and the Analysis of the Ego, from Freud, the essay outlined the trajectory of the concept of group throughout Adorno's work until the culmination of a social psychology analytically oriented. In conclusive terms, it bets that the conditions that lead the individual to \&quot;become\&quot; the groups are related to the social objectivity that promotes the irrationality through the commodification and reification of the social relations.
\end{abstract}

Keywords: Social Psychology; Group Psychology; Critical Theory of Society.

\footnotetext{
${ }^{1}$ Mestrando em Psicologia pela Universidade Federal do Pará

2 Doutor em Psicologia (2007) pela Universidade de São Paulo. Exerce atualmente o cargo de Professor Adjunto IV no Instituto de Filosofia e Ciências Humanas da Universidade Federal do Pará e atua como líder do grupo Psicanálise, Conflito e Cultura (UFPA), vinculado ao Diretório de Grupos de Pesquisa do CNPQ.
} 
Uma das consequências da Revolução Industrial que alteraram significativamente os rumos da história foi a migração de um grande contingente populacional em direção aos centros urbanos. Eis o nascimento da massa: um amplo número de pessoas que, ao dividir rotineiramente os espaços urbanos, poderia se comportar coletivamente de forma distinta do indivíduo em sua particularidade, sendo então um dos principais produtos do capitalismo industrial dos séculos XVIII e XIX.

Realizar um estudo sobre as massas poderia ser comparado, sem embargo, a percorrer um caminho sinuoso rodeado por abismos. Com efeito, é necessário se esquivar constantemente de caracterizações reducionistas que subtraem da massa seu caráter dinâmico, multiforme e complexo. O recurso a leituras meramente ideológicas também é um obstáculo a ser desviado, evitando, por conseguinte, tanto uma atitude de desprezo dasmassas (a massa como ralé, hoipolloi), quanto de adulação (a massa como propagadora de potenciais altruístas e transformadores). Ambas as leituras pretendem domesticar o pensamento sobre as massas sob sua curatela, tornando-as mais próximas de panfletos políticos do que de estudos acadêmicos relevantes (SLOTERDIJK,2002).

Diante desse cenário, seria cômodo propor uma solução teórico-metodológica que pudesse livrar o percurso de tais obstáculos. Entretanto, o próprio ato de circunscrição de um estudo de psicologia das massas sob uma rubrica teórica qualquer é um desafio per se. Neste sentido, o esforço constante é o de evitar o recurso tanto a uma abordagem psicologizante quanto a explicações que subtraem a subjetividade do contexto social $\mathrm{O}$ que pretendemos então, dentro do alcance de um estudo de iniciação científica, é estabelecer uma análise que contemple a porosidade das (supostas) fronteiras do psicológico e do social.Utilizando os referenciais teóricos da psicanálise e da teoria crítica, poderemos contemplar, ainda que de forma introdutória, a complexidade da problemática das massas.

Nesse sentido, estabelecer um debate entre a psicologia das massas freudiana e o pensamento de Theodor W. Adorno nos apresenta um caminho para compreender as massas não só em busca de fatores psicológicos, mas também do seu papel decisivo dentro do tecido social. Destarte, promovemos uma necessária interlocução entre a psicologia e a teoria social, saberes cuja separação atende, segundo Adorno ([1953]2015), mormente a fins metodológicos, uma vez que não é possível determinar em que aspectos a massa, por exemplo,seria um fenômeno puramente psicológico ou social. No fim das contas, supor que tal separação tenha de ser feita reflete uma divisão do trabalho dentro das ciências análoga àquela que ocorre no todo social. Mais ainda, a separação entre sociedade e psique como 
decreto metodológico reflete, igualmente, a cizânia entre o sujeito e a objetividade social que promove a alienação deste mesmo sujeito em relação à dinâmica social.

Se para Adorno ([1953]2015) a separação entre explicações sociais e psicológicas é arbitrária, a harmonização entre estas perspectivas é também um movimento extrínseco ao que se dá na realidade social. Ao fim e ao cabo, a busca por uma espécie de "hibridismo psicossocial" é movida por uma falsa consciência que vigora sob o véu da ideologia: de tal maneira, promove-se na teoria a resolução do conflito entre indivíduo e sociedade, entes irreconciliáveis entre si. É verdade que os indivíduos são produtos da totalidade social. Porém, quanto mais eles adentram a sociedade, mais aguda se torna a contradição entre os dois.

Entre a psicologização do social e a sociologização do psíquico, a abordagem adotada tanto por Freud quanto por Adorno para a psicologia das massas realiza um dispendioso exercício: uma dialética sem síntese, que abriga em seu seio esta contradição. A psicanálise, por exemplo, subjaz da dinâmica histórica que a um só tempo criou e mutilou o indivíduo. Este conflito não é silenciado, mas escutado e valorizado dentro da psicanálise como prática e teoria. A contradição é índice de uma verdade, ainda que dentro de uma realidade inconsciente (JACOBY, 1975).

De maneira semelhante, o gesto fundamental da Teoria Crítica é o de apreender a contradição teórica como sinal de uma contradição social efetiva. Daí a recusa em promover, mais uma vez, a harmonia entre o que é reciprocamente antagônico (ŽIŽEK, 1992). Se a massa, por exemplo, é um espaço no qual podemos vislumbrar tanto o conflito psíquico quanto a dialética dos processos sociais, não convém determinar as noções de conflito psíquico e dialética como análogas em diferentes níveis de abstração. Portanto, reitera-se a importância de um estudo como o que foi aqui realizado, que, ao se comprometer em analisar o tema a partir de um ponto de vista situado entre o psicológico e o social, compromete-se também a contemplar o caráter diverso e multiforme das massas. Isto é, sem promover explicações que hipostasiem a dimensão psíquica ou social do fenômeno.

Destarte, o presente estudo buscou empreender uma analise introdutória da psicologia das massas em alguns dos trabalhos de Sigmund Freud e de Theodor W. Adornovisando estabelecer uma caracterização que situe as massas entre o psicológico e o social. Neste sentido, pesquisa aqui desenvolvida é de natureza teórica e tem na revisão bibliográfica seu principal modo de obtenção de dados 


\section{"Toda psicologia é social": a noção freudiana de massa}

A investigação sobre a psicologia das massas teve princípio no final do século XIX, com destaque para a obra Psicologia das Multidões, de Gustave Le Bon. Neste estudo, Le Bon([1895]1995)pretendeu executar a imperiosa tarefa de estudar as massas, cuja ascensão era, para ele, um sinal do desgaste dos princípios fundamentais da civilização e o prelúdio de um estágio de total caos social que em breve sobreviria. Ao participar de uma massa, diz Le Bon ([1895]1995), os indivíduos estabelecem para si uma alma coletiva que os faz sentir, agir e pensar de forma bem diferente em relação ao comportamento individual de cada um de seus componentes. O indivíduo se deixa guiar pela ação inconsciente da multidão, sacrificando seus atributos pessoais ao submergir neste contexto de homogeneidade, como se o "médico" mais cordato pudesse se tornar um "monstro" incontrolável.

Ainda segundo Le Bon ([1895]1995), dentre os atributos que derivam das tendências inconscientes que sobrevêm na multidão,um dos mais preponderantes é o de ser sugestionável por um líder. Com efeito, a partir de um habilidoso manejo da hipnose e da sugestão, o líder de uma multidão poderia fazer dela joguete para o cumprimento de seus interesses por meio da afirmação de ideais e crenças que deveriam ser ostensivamente repetidas a fim de agitar a alma coletiva, estivesse ela reunida no mesmo lugar ou de forma gradual e insidiosa em grupos menores.

O mote da sugestionabilidade como núcleo da psicologia das massas se faz presente também em outros estudos da época, como os de Tarde ([1888]1993) e McDougall([1920]1973), ainda que a noção de sugestão tenha sido apresentada como "indução primária" por este e como "imitação" por aquele. Com efeito, podemos apontar que estes autores distinguem categoricamente as disposições psicológicas individuais experimentadas pelo sujeito daquelas que ele experimentaria ao participar de uma massa. A massa seria, ao fim e ao cabo, um corpo social dotado de uma psicologia particular capaz de promover uma contaminação de afetos entres os seus membros. Contudo, esta psicologia particular da massa se constituiria às custas do rebaixamento intelectual dos seus membros, tornando-se por isto propensa à barbárie e à destrutividade características de uma suposta condição primitiva. Não nos parece difícil perceber que o desprezo pelas massas é a tônica destes primeiros estudos sobre o tema, e cremos não ser exagerado pensar que tais autores, na verdade, referiam-se de forma elitista ao proletariado das zonas urbanas ao atribuir traços bárbaros à massa. 
Por outro lado, no início do texto Psicologia das Massas e Análise do Eu, Freud([1921]2011) deixa clara sua posição acerca da oposição entre psicologia individual e psicologia social:

A oposição entre psicologia individual e psicologia social ou das massas, que à primeira vista pode parecer muito significativa, perde boa parte de sua agudeza se a examinamos mais detidamente. É certo que a psicologia individual se dirige ao ser humano particular, investigando os caminhos pelos quais ele busca obter a satisfação de seus impulsos instintuais, mas ela raramente, apenas em condições excepcionais, pode abstrair das relações deste ser particular com os outros indivíduos. $\mathrm{Na}$ vida psíquica do ser individual, o Outro é via de regra considerado enquanto modelo, objeto, auxiliador e adversário, e portanto a psicologia individual é também, desde o início, psicologia social, num sentido ampliado, mas inteiramente justificado (FREUD, [1921]2011, p. 14)

Assim, toda psicologia é social em alguma medida. A mais precoce ligação de um ser humano com o mundo ao seu redor é, sem dúvida, mediada por eventos e processos intrapsíquicos que configuram uma relação social. Por mais que se avente a ideia de que exista um "universo" acessível apenas ao indivíduo (supondo que este acesso seja completo e satisfatório), este universo da interioridade é construído a partir de elementos captados mediante um processo que concilia a experiência com a realidade fora-de-si e a percepção, ainda que rudimentar, destas experiências neste espaço dentro-de-si. A experiência do indivíduo na massa é, para Freud ([1921]2011), divisível e passível de decomposição, mas também é relacionada a eventos e experiências primordiais dentro de uma estrutura familiar.

Nesse sentido, os sentimentos de irresponsabilidade, poder e impulsividade que o indivíduo experimenta na massa não são tributários de uma psicologia própria da alma coletiva, mas sim do arrefecimento das defesas e censuras psíquicas de cada um dos seus membros. Freud também desmistifica o entendimento de que os indivíduos agem de maneira diferente na massa porque se sugestionam, imitam ou contagiam entre si. Não há, segundo Freud ([1921]2011), fundamentos que expliquem a natureza da sugestão, fazendo deste conceito um "véu" para uma explicação muito mais aguda para a psicologia das massas. Em vez disto, Freud ([1921]2011) argumenta que as massas se ligam por meio da libido - isto é, a expressão de pulsões ligadas àquilo que é abrangido pela ideia de "amor" em sentido lato: amor sexual, mas também amor parental, filial, fraternal, etc.

Com efeito, para Freud ([1921]2011) a relação entre os membros da massa faria mais sentido se descrita sob a forma da identificação, a qual, em linhas gerais, ocorreria quando o eu é moldado partir de certo modelo. Nestes termos, partindo da identificação primordial que ocorre no complexo de Édipo, os processos identificatórios podem se dar, por exemplo, substituindo um investimento libidinal pela introjeçãodo objeto no Eu. Além destas duas 
situações, a identificação pode ocorrer quando se percebe elementos em comum, como ideias ou afetos, em uma pessoa que não é objeto das pulsões sexuais.

No que se refere à massa, Freud ([1921]2011) observa o último tipo de identificação descrito acima, já que os indivíduos nutrem entre si um sentimento de irmandade motivado pela disposição afetiva comum a todos, que é a ligação com o líder. Freud ([1921]2011) chama nossa atenção, no entanto, para o fato de que este eu que se identifica com outros é um eu cindido em diferentes instâncias, uma sempre vigiando e policiando a outra. A influência do meio e os objetos introjetados acarretam na especialização desta instância, que Freud ([1921]2011) denomina de ideal do eu. O ideal do eu está no cerne da influência e admiração exercida pelas autoridades desde o seio familiar e serve de modelo para o processo de identificação do indivíduo com a cultura.De tudo isto, podemos, pois, concluir que uma massa simples se constitui quando vários indivíduos colocam um mesmo objeto (o líder) como seu ideal do eu e, por conseguinte, identificam-se entre si.

Esse seria o fundamento da massa para Freud ([1921]2011), que, em oposição ao gregarismo de Trotter ([1919]1953) e seu instinto de rebanho, enfatiza mais ainda a importância da relação com o líder para a sociabilidade das multidões. Diz Freud ([1921]2011) que cada indivíduo espera ser amado de forma especial pelo líder. Contudo, se este amor especial fosse levado a cabo, o sentimento de justiça seria violado e a harmonia social se desfaleceria, pois a natureza do laço social se dá a partir da igualdade da renúncia individual.

Freud ([1921]2011) afirma que, em vez de ser animal de rebanho, o homem é animal de horda e a massa é uma reedição da horda primeva que descreveu em Totem e Tabu(FREUD [1913]2013). A relação dos indivíduos entre si na massa revive a relação entre os irmãos que compartilhavam a obediência ambivalente a um pai severo e que monopolizava o gozo com suas atitudes dominantes e implacáveis, cuja semelhança com o líder da massa seria evidente. Ainda que o indivíduo não possa ser totalmente relatado a esta metáfora, uma vez que participa de vários agrupamentos ao mesmo tempo ao longo de sua história, Freud ([1921]2011) chama atenção para o fato de que, em alguma medida, tanto a horda quanto a massa dizem respeito às especificidades da relação entre eu e ideal do eu. O líder/pai primordial experimenta uma separação menos aguda entre as duas instâncias: seu ideal do eu chega a se confundir com seu eu, resultando em uma atitude narcísica por vezes exacerbada e passando a impressão de força inequívoca. 
A partir da próxima sessão do estudo, veremos como todos esses aspectos da teoria freudiana acerca das massas se fizeram presentes na obra de Theodor W. Adorno, principalmente na construção de uma psicologia social analiticamente orientada.

\section{$O$ conceito de massa na primeira teoria crítica}

\section{As massas no escopo da Dialética do Esclarecimento.}

$\mathrm{Na}$ coletânea de ensaios que compõem a Dialética do Esclarecimento, Adorno e Horkheimer denunciam, diante dos horrores da Segunda Guerra Mundial, os descaminhos do Esclarecimento (Aufklärung) como filosofia que identifica o sistema da ciência com a verdade (ADORNO; HORKHEIMER, [1947]1985c). O progresso alardeado pelo Esclarecimento não libertou os homens de sua menoridade, mas condenou-os a regredir a estágios bárbaros. Tanto o horror dos regimes totalitários quanto a fetichização das relações e a decadência ideológica da indústria do entretenimento nas sociedades ditas liberais seriam, pois, sucedâneas de um falso esclarecimento. Em ambos os casos, as massas não seriam apenas objetos de uma dominação perpetrada por meio de uma ilusão de progresso, mas principalmente o próprio veículo dessa dominação (ROBERTS, 2008).

Para Adorno e Horkheimer ([1947]1985a), a mesma lógica de dominação exposta acima se imprime na cultura contemporânea, conferindo a tudo um caráter de semelhança e equivalência, algo largamente motivado pela especialização de uma indústria responsável pela produção em massa de bens culturais por um coeso sistema composto pelos meios de comunicação e os detentores do poder econômico e político. Ao engendrar produtos supostamente feitos sob medida para as massas, a Indústria Cultural insinua falaciosamente que as massas são o seu principal objeto e motivação. Na verdade, as massas são a própria ideologia da Industria Cultural: a mentalidade a ser nelas insuflada é a maior finalidade da padronização de bens. Tudo pode ser tornado homogêneo e mercantilizável, inclusive os indivíduos(ADORNO, [1969]1985).

Pois bem, podemos ver que a perda de identidade característica da psicologia das massas de Le Bon a Freud é aqui realizada de maneira programática. Os frankfurtianos, no entanto, avançam ao situar as massas como produto social a ser constantemente reconduzido a participar dos estágios do capitalismo. O papel da Indústria Cultural seria padronizar e reificar todos os aspectos da realidade, transformando o banal em mercadoria, monetizando o monótono. Toda eventual espontaneidade que surgir no seio da massa é rapidamente 
transformada em mercadoria: a indústria cultural está sempre em busca de vestes novas para antigos estereótipos - o novo hit do verão, o novo filme de super-heróis, etc. Assim, a consciência se transforma em conformismo, a espontaneidade artística em entretenimento pronto para consumo. É justamente esta falta de espontaneidade que faz com que Adorno e Horkheimer rejeitem o termo Cultura de Massa, o qual poderia levar a crer que os produtos da indústria do entretenimento seriam advindos das próprias massas, e não de um conluio sadomasoquista destas com a indústria do entretenimento, indústria esta devotada a utilizar o impulso categorizador do esclarecimento para a geração de dividendos financeiros por meio da mistificação das massas, manejando seus desejos por meio da promessa do gozo irrestrito mediante o consumo (WHITEBOOK, 2008).

Segundo Adorno e Horkheimer ([1947]1985b), a falência do projeto do Esclarecimento também se manifesta nas massas dentro do esquema dos regimes totalitários, como exposto no ensaio Elementos do Antissemitismo. Aqui a percepção da idiossincrasia, do estranho e do Outro é adquirida via um pensamento de ticket no qual "a experiência é substituída pelo clichê e a imaginação ativa na experiência pela recepção ávida"(ADORNO; HORKHEIMER, [1947]1985b, p.165). Se a psicanálise revelou os potenciais de ação de um indivíduo segundo uma laboriosa dialética interna entre instâncias psicológicas que se digladiam, a cultura contemporânea acaba por revelar que pode expropriar esse indivíduo da sua própria economia pulsional, submetendo-o ao aceite dócil de palavras de ordem proferidas incessantemente às massas.

No exemplo do antissemitismo, o imperativo de perceber o judeu como ameaça a ser aniquilada teria subsídios psicológicos na falsa projeção daquilo que é da ordem do Inquietante (Unheimlich) em Freud ([1919]2010): a percepção daquilo que é estranho como intimamente familiar, daí a ocorrência da falsa projeção daquilo que em "mim” é inaceitável em direção ao Outro, o qual monopolizaria todas as indesejáveis idiossincrasias que precisam ser eliminadas e oprimidas. Conquanto isto seja algo realmente experienciado pelo indivíduo, não se trata, todavia, de algo que ocorra espontaneamente em cada um dos indivíduos na massa. A realidade social reificada opera no sentido de promover o triunfo do pensamento de ticket sobre a reflexão (ADORNO; HORKHEIMER, [1947]1985b).

Podemos visualizar, no final das contas, que o interesse sobre as massas no escopo da filosofia social empreendida na Dialética do Esclarecimento diz respeito muito mais ao seu papel dentro da realidade social na qual há o desfalecimento da razão esclarecida, agora redirecionada para fins torpes. O livro, como culminância da parceria de Adorno e Horkheimer, convoca a psicanálise como colaboradora para uma compreensão histórica e 
filosófica do status social do capitalismo tardio. Veremos, porém, que a psicologia das massas freudiana seria mais profundamente reinterpretada nos trabalhos seguintes de Adorno, que edifica sua psicologia social analiticamente orientada sobre o alicerce teórico provido mormente em Psicologia das Massas e Análise do Eu (FREITAS, 2010).

\section{À guisa de uma definição}

Se na Dialética do Esclarecimento a temática das massas foi usada ad hoc por Adorno e Horkheimer para compreender os descaminhos do esclarecimento no capitalismo tardio, nos textos "O grupo" (ADORNO; HORKHEIMER, [1956]1978b) e "A massa" (ADORNO; HORKHEIMER, [1956]1978a) os autores lançam luz de forma direta sobre a questão das massas em uma intensa interlocução com o texto freudiano sobre o tema. Nestes termos, para Adorno e Horkheimer ([1956]1978b), o indivíduo se insere na totalidade social por meio de instâncias intermediárias que podem ser referidas ao conceito de grupos: comunidades de interesses que aglomeram indivíduos vinculados por características objetivas. Ainda que o grupo possa reclamar para si o papel de mediar as relações entre o indivíduo e o todo social, não haveria como sustentar tamanha autonomia dos grupos em relação à dinâmica mais ampla da sociedade. Um grupo familiar não é um microcosmo incólume diante da realidade social, mas sim uma instância intermediária entre o indivíduo e a sociedade que é dramaticamente afetada se um dos seus membros perde o emprego, por exemplo.

Para o estado de coisas do capitalismo, entretanto, essa pretensa função mediadora do grupo é conveniente, porquanto o grupo pode assumir para si a responsabilidade pelas mazelas do contexto social mais amplo. Daí podemos visualizar que o grupo, na verdade, faz uma mediação reificada da realidade social ao promover a reconciliação do indivíduo com a sociedade ao incutir nele o valor da identidade grupal, transformando as chagas provenientes do contato com a sociedade em componentes de uma suposta "personalidade" derivada do grupo.

Ainda que reificada, a identidade é um valor central para a noção de grupo.Na massa, contudo, a identidade é um construto a ser abdicado em prol de um anonimato homogeneizante. Este aspecto não foi destacado à toa pela primeira tradição da psicologia das massas, representada principalmente por Gustave Le Bon. Segundo Adorno e Horkheimer ([1956]1978a), identificar a massa a uma turba de autômatos embrutecidos é um movimentochave para oferecer aos detentores do poder uma espécie de fisionomia que os permita o 
controle social do "populacho". Eis aí a denúncia de que a psicologia das massas se colocou, em princípio, a serviço do poder, sendo usada como instrumento do totalitarismo ${ }^{3}$.

É nesse sentido que Theodor Adorno e Max Horkheimer valorizam a inovadora posição de Freud em relação às massas. A vacuidade em termos políticos do texto freudiano acabou por ser uma qualidade, uma vez que se afastou da tradição de desprezo das massas de alguns dos seus antecessores, notoriamente mancomunados com as elites. Para além de reconhecer as massas como um "barril de pólvora", Freud ([1921]2011) foi capaz de vislumbrar que na massa o egoísmo pode se transformar em altruísmo e cooperação por meio da restrição ao narcisismo exacerbado e do sentimento de comunidade com aqueles que também se identificam com o mesmo líder ${ }^{4}$.

Adorno e Horkheimer ([1956]1978a) de fato reconhecem que os ensinamentos de Freud ([1921]2011) anteciparam, em certa medida, a compreensão do horror nazifascista que eclodiria anos depois na Europa, mas também identificam problemas na abordagem freudiana. Por exemplo, no que se refere à proposição do vínculo social em termos meramente psicológicos, já que, seguindo este raciocínio, perderíamos de vista o fato de que a massa só se forma sob condições sociais específicas, tendo nascido em um estágio do capitalismo industrial propício à sua reapropriação pelas ideologias totalitaristas. Com efeito, a variedade de contextos sociais nos quais as massaspodem participar decisivamente não pode ser contemplada por fórmulas psicologizantes que, ao enfatizaremem demasia aspectos anímicos, olvidam que o real perigo reside naqueles que delas (das massas) se aproveitam politicamente para atender a interesses pessoais ou de oligarquias dominantes.

Nesse sentido, é justamente o interesse pelo modo como, na massa, o indivíduo subscreve a interesses sociais e políticos que atentam flagrantemente contra a sua própria racionalidade que mobilizará os estudos subsequentes de Adorno. Como veremos a seguir, sob a insígnia de uma psicologia social analiticamente orientada.

\section{O retorno a Freud como alicerce da psicologia social adorniana}

O interesse de Adorno pela psicanálise freudiana é, de certa maneira, evidente desde a década de 20, quando o filósofo apresentou o manuscrito $O$ conceito de inconsciente e a teoria

\footnotetext{
${ }^{3}$ Nestes termos, vale lembrar que já em MeinKampf Hitler expressava a convicção de que um líder deve dirigir sua propaganda às massas por estas serem emotivas e pouco interessadas em verdades objetivas.

${ }^{4}$ Relembremos que em Freud ([1921]2011) a identificação com o líder é herdeira da identificação com o pai, porquanto o líder é colocado na posição do ideal do eu. Tal situação subsidia a compreensão do "masoquismo de massa": a tendência da massa de se submeter a um líder forte e de ojerizar o estranho e o não-idêntico.
} 
transcendental da psique como tese de habilitação para a docência, tese que foi recusada por Hans Cornelius, então seu orientador. $\mathrm{Na}$ década seguinte, o filósofo se dedicou principalmente a estudos que realizavam críticasculturais e estéticas, sobretudo em questões relacionadas à música. Neste período, fica ainda mais evidente o compromisso de Adorno com a rejeição de especulações teóricas que suprimissem a dimensão subjetiva presente na dialética de si, recusando ainda concepções que promovessem a reconciliação com o irreconciliável isto é, visões de mundo que omitem a violência impingida ao indivíduo pela sociedade, a falsa consciência de harmonia social como ideologia (JAY, 2008).

Com efeito, a psicanálise se mostrou para Adorno uma ferramenta com altíssimo potencial crítico, já que, em si mesma, continha uma dialética evidente entre o esclarecimento e o não-esclarecimento, entre o consciente e o consciente e assim por diante. Como vimos acima, a psicanálise foi usada como um instrumento auxiliar na crítica do Esclarecimento, crítica esta promovida na célebre obra que marcou o ápice da intensa parceria intelectual entre Theodor Adorno e Max Horkheimer. Se, após a Segunda Guerra, Horkheimer se afastou relativamente da psicanálise em seus trabalhos individuais, Adorno persistiria na sua utilização de maneira contumaz para fins de crítica, alcançando uma "infraestrutura" psíquica totalmente interpenetrada pela "superestrutura" social e vice-versa (DAHMER, 2011).

Apesar de todo o histórico da sua relação intelectual com a obra de Freud, a partir dos anos 50 Adorno faz um movimento ainda mais agudo de leitura e interpretação da psicanálise freudiana. A particularidade da interpretação adorniana de Freud reside na intransigência ao defender alguns dos seus valores centrais, como, por exemplo,a importância do conflito psíquico. No texto "A psicanálise revisada", Adorno ([1951]2015a) deixa clara tal posição ao se opor às tendências revisionistas da psicanálise que, à época, tentavam "atualizar" a obra freudiana e "libertá-la" dos valores patriarcais e repressivos da sociedade em que ela surgiu 5 . Ao fim e ao cabo, para Adorno ([1951]2015a) os neofreudianos acabavam por pregar um discurso de adaptação do indivíduo à sociedade, tentando dessexualizar a psicanálise em defesa de antigos preconceitos morais com nova a maquilagem do conceito liberal de "bemestar".

Ainda para Adorno ([1951]2015a), a condenação de Freud como pensador pessimista é uma estultice. Talvez o pessimismo freudiano seja muito mais humano do que a apologia

\footnotetext{
${ }^{5}$ Revisionistas como Karen Horney e Erich Fromm apostavam na redução da ênfase na sexualidade e seus mecanismos subjacentes de repressão em busca de uma teoria que valorizasse mais os potenciais pró-sociais do ser humano em direção a um horizonte de "liberdade". Desta maneira, estes "neofreudianos" procuravam substituir explicações que antes eram subsidiadas pela repressão pulsional por outras que eram, na verdade, apenas epifenômenos deste mesmo mecanismo repressivo, como, por exemplo, a "falta de amor".
} 
vazia que os seus detratores faziam do amor, transformando-oem um dispositivo conformista. Adorno ([1951]2015a) lamenta que essa corrente teórica tenha tentado resolver as lacunas existentes na obra de Freud (como a ausência de crítica ao princípio da realidade, por exemplo) por meio de um discurso adaptativo que, no fim das contas, está eivado de ideologia.

$\mathrm{Na}$ direção contrária, Adorno toma Freud de forma radical para pensar as relações entre indivíduo e sociedade de forma crítica. Funda, assim, uma psicologia social sui generis e que não se reduz a uma mera interação entre psicologia e sociologia, apreendendo a complexidade do seu objeto de pesquisa - a saber, os comportamentos irracionais manifestados nas massas sem cindi-lo a priori por meio de decretos metodológicos (CROCHÍK, 2011). Visualizando o eu como instância que promove a dialética entre o que é consciente e inconsciente, Adorno problematiza as condições sociais objetivas da irracionalidade subjetiva que acometem o eu de forma imanente (ADORNO, [1955]2015).

Assim, com Adorno a psicologia das massas de origem freudiana deixa de ser mero complemento a um programa de crítica da sociedade, tornando-se a própria lente teórica a ser desdobrada nas análises tanto de objetos ordinários fornecidos pela indústria da cultura como, por exemplo, a coluna de astrologia do jornal Los Angeles Times, cuja análise culminou no livro As Estrelas Descem à Terra (ADORNO, [1953]2015) - quanto das vicissitudes do uso da psicologia das massas no discurso de agitadores fascistas dos EUA, cujos métodos foram comparados por Adorno ([1946]2015) às técnicas de propaganda fascista que o regime hitlerista lançara mão poucos anos antes. É o que veremos a seguir.

\section{A reapropriação adorniana de Freud na análise da propaganda fascista}

A análise do fascismo foi uma preocupação perene ao longo da obra de Theodor Adorno, uma vez que o filósofo foi testemunha da eclosão do regime totalitarista de Hitler e, posteriormente, obrigado a deixar a Alemanha por conta de sua ascendência judaica (WIGGERSHAUS, 2002). Exilado nos Estados Unidos, Adorno pôde observar que o fascismo não era produto apenas de um determinado contexto histórico ou geográfico, mas sim uma ameaça insidiosa que se escamoteara inclusive dentro de democracias supostamente liberais. É neste sentido que, entre os anos 40 e 50, Adorno compara o discurso de agitadores políticos conservadores às técnicas de propaganda fascista utilizadas pelo Reich. Como bússola teórica, Adorno convoca a psicologia das massas freudiana e aponta as especificidades de seu uso por aqueles que frequentemente chama de "demagogos". 
Adorno ([1946]2015) aponta que o discurso dos referidos demagogos é predominantemente direcionado a mexer com as disposição psicológicas dos seus ouvintes em detrimento de argumentos objetivos. Neste sentido, Adorno chama a atenção para o fato de os agitadores se apresentarem como um misto de homem comum e semideus. Colocados na posição de anunciadores do porvir, os demagogos insistem que sua força reside justamente na falta de pudor em confessar suas fragilidades. O demagogo se destaca porsupostamente compartilhar um segredo sobre o futuro que faz os ouvintes se sentirem parte de uma elite prestigiada. Reparemos que todo o discurso é erigido em cima de estratagemas de persuasão que lançam uma cortina de fumaça sobre o teor político objetivo do discurso, o que permite que esse tipo de propaganda se preste a atacar "fantasmas" - isto é, um imaginário do que venha a ser o comunista, por exemplo, em vez de pessoas com atributos reais e não fantasiosos.

Todas essas ideias são expressas não por um fluxo lógico de argumentos, mas sim pela repetição incessante de motes e slogans que mexem com os afetos do ouvinte. O seguidor deste tipo de demagogo sente prazer ao ouvir o discurso e se encontra propenso a consumir, tal qual consome um filme ou novela, a narrativa que esconde a ideologia política dos líderes. Os líderes impõem seu protagonismo justamente pelo desembaraço em violar tabus sociais em seus discursos, falando "sem papas na língua" daquilo que supostamente todos pensam, mas nunca tiveram coragem de expressar. Desta maneira, conseguem exprimir discursivamente e sem pudor algum a oposição entre "nós" e os "outros", "amigos" e "inimigos". Em sua oratória, o demagogo fascista consegue conduzir as massas a odiar e desejar aniquilar os “inimigos" eleitos.

É nessa esteira que Adorno ([1951]2015) retoma Freud, apontando como o orador fascista produz de forma artificial e calculada o vínculo libidinal na massa. Ele pretende com isto ser o caudilho que desperta o que nos indivíduos há de arcaico e primitivo por meio de estímulos psicológicos totalmente pauperizados de conteúdo objetivo. Com efeito, os líderes fascistas se apresentam como dignos de serem os ideais do eu da massa, provocando nela afetos expressos por ligações libidinais. É justamente o arrefecimento das barreiras que impedem essa libido de se expressar totalmente que propiciam afetividade e impulsividade exacerbadas.

No entanto, diz Adorno ([1951]2015), o fascismo: “...não é simplesmente a reocorrência do arcaico, mas sua reprodução na e pela própria civilização" (p.162). Daí temos que ter em conta que, na propaganda fascista, o amor como vínculo da massa dá lugar à obediência. Se o líder fascista se coloca na posição de pai, não é a do pai amoroso, mas a do 
pai tirano da horda primitiva, que monopoliza o gozo e ameaça os filhos com punições severas. Além de modelo a ser copiado, o líder fascista se torna, mediante o esquema de propaganda, a personificação idealizada dos atributos desejáveis para a massa. Por isto, nas sociedades fascistas a obediênciaé racionalizada segundo uma hierarquia: o indivíduo é passivo com seus superiores e implacável com os subordinados.

Diante de todo esse cenário, Adorno ([1951]2015) conclui que “...o que acontece quando as massas são subjugadas pela propaganda fascista não é uma expressão primária e espontânea de pulsões e demandas, mas uma revitalização quasi-científica de sua psicologia" (p. 186). Com efeito, notemos como o trunfo freudiano foi o de, talvez involuntariamente, antecipar que o ato de abandono do narcisismo individual em nome do investimento libidinal em um ideal do eu personificado em um líder seria uma condição indispensável a ser levada a cabo para a dominação das massas. O indivíduo monadológico e atomizado das coletividades fascistas encontra, de tempos em tempos, grande correspondência com o indivíduo assujeitado pela reificação de todas as suas relações de trabalho, afetividade e consumo nas ditas sociedades liberais. Com uma perplexidade obscurecida pelo tom dialético e amplo da análise, Adorno ([1951]2015) denuncia que o fascismo reverbera para muito além dos livros de história, grassando com perigosa desenvoltura pelas décadas que sucederam os anos da Segunda Guerra Mundial.

\section{Considerações Finais}

Após todo esse percurso, torna-se interessante notarcomo o sinuoso caminho inerente ao debate sobre a psicologia das massas em Freud e Adorno nos propiciou alguns desdobramentos que podem, à guisa de considerações finais, ser brevemente expostos. Em primeiro lugar, a atualidade do texto Psicologia das Massas e Análise do Eu é algo a ser destacado: acreditamos que o texto é um tratado preciso sobre como o indivíduo é marcado pelas relações que trava com o outro, com o estranho, o fora-de-si desde o princípio de sua constituição, eventos que serão preponderantes para toda a sua vida em sociedade. Além disto, Freud parece nos fornecer uma espécie de "dossiê" sobre as formas de servidão às quais os indivíduos se prestam, submetendo-se aos interesses de lideranças que podem nos conduzir pela via da afetividadee por meio de disposições inconscientes, relegando à massa uma posição de masoquismo servil. 
Tivemos a oportunidade também de, ao longo deste estudo, compreender a complexa trajetória do conceito freudiano de massa ao longo da obra de Theodor W. Adorno. Sem dúvida, a reapropriação dialética empreendida pelo filósofo alemão desdobrou a psicologia das massas de Freud em uma psicologia social analiticamente orientada que procura compreender como as massas se submetem a programas que ameaçam seus interesses racionais. Isto tanto nas coletividades regidas pela insígnia do totalitarismo nazifascista quanto nas massas que se acotovelam nas grandes metrópoles urbanas, para as quais todo os possíveis destinos parecem já ter sido traçados por um sistema de decisões políticas que anda de mãos dadas com a indústria do entretenimento. Desta maneira, somos alienados e reificados tanto em nosso tempo de trabalho quanto em nosso suposto "tempo livre".

Em retrospecto, tudo isso nos leva a examinar o conteúdo aqui exposto em busca de potenciais respostas para o lúgubre cenário de dominação que as massas parecem ter sido expostas desde seu advento. No entanto, este mesmo exame nos leva a considerar que não deve haver resposta que não recorra a uma imagem ideológica do mundo, imagem esta que escamoteia problemas sob uma falsa consciência da realidade social. O contato do indivíduo com a sociedade, ainda que intermediado por grupos e massas (e justamente por isso, talvez) é marcado por cicatrizes e traumas. Em Freud, é evidente que a civilização se impõe sobre o indivíduo pela via da violência, a qual principia já na renúncia às moções pulsionais que o indivíduo tem de se defrontar ao longo de seu convívio em sociedade. A máxima adorniana de que indivíduo e sociedade são irreconciliáveis entre si também nos poderia levar a descartar possíveis pontos de fuga a essa realidade.

No entanto, concluímos que a intensa relação intelectual entre Freud e Adorno aqui exposta seria equivocadamente aproveitada se nos conduzisse a um niilismo passivo e resignado. A educação dirigida à autorreflexão crítica, tanto em termos individuais quanto grupais, permitiria a elaboração de um passado marcado por momentos de irracionalidade subsidiada por condições objetivas concretas. Conhecer essas condições que nos levam a agir irracionalmente é um primeiro passo para uma desbarbarização emancipatória. Em outras palavras, de posse das noções aqui expostas, cabe (re)conhecermos as condições que nos levam a ser massa.

Esse tipo de exercício é diário e exaustivo. Entretanto, vejamos o que se desenha como a realidade social contemporânea: nas manifestações, protestos, programas de televisão e etc., esta autorreflexão crítica está sempre excluída dos discursos. Atores políticos que parecem ter sido a inspiração de Adorno para redigir os textos sobre a propaganda fascista alastram-se despudoradamente no cenário local e nacional, ameaçando todas as conquistas no âmbito de 
direitos humanos e proteção social. Saber reconhecer a psicologia das massas presente no discurso deste tipo de agente social, repleto de gatilhos psicológicos, apelos à emoção e ataques pessoais a adversários reais ou imaginários pode ser uma saída de extrema valia diante da plêiade de opções que temos disponíveis para sermos apenas e tão somente uma massa conduzida por um ou mais líderes - estejam eles nos palanques políticos ou nas telas de televisão.

Em uma palavra, após todo esse percurso acreditamos haver propiciado uma fisionomia ampla, dentro do alcance de um estudo de iniciação científica, das condições em que somos conduzidos por meio de uma realidade social reificada a nos comportarmos como um “rebanho". Esta seria a função de um trabalho que se propôs a seguir o caminho da psicologia social analiticamente orientada: articular as moções pulsionais com a dinâmica social, sem pretensões de reconciliação entre os dois âmbitos, mas sim tentando visualizar como ambos determinam a um só tempo os processos de mudança social que determinam, em um nível privado, a economia pulsional dos indivíduos e seu comportamento em contato com a coletividade.

Segundo Adorno ([1955]1995), o objetivo de toda a educação a ser realizada após Auschwitz é evitar que tal horror se repita. Para tanto, precisamos lutar por uma educação desbarbarizantee acessível para todos desde a primeira infância, e também construir um clima de discussão social que exponha os horrores do progresso e os progressos do horror na contemporaneidade. De posse de tudo isto, cremos que o presente trabalho promoveu um diálogo profícuo entre dois pensadores que favorecem esse movimento de tomada de consciência. Afinal de contas, ambos não promovem a condenação da razão enquanto tal: em vez disto, fazem a ressalva de que a razão também produz monstros.

\section{REFERÊNCIAS BIBLIOGRÁFICAS}

ADORNO, T.W. Antissemitismo e propaganda fascista.In: Ensaios sobre psicologia social e psicanálise. São Paulo: Editora Unesp, 2015, 137-152. (Trabalho original publicado em 1946)

A psicanálise revisada.In: Ensaios sobre psicologia social e psicanálise. São Paulo: Editora Unesp, 2015, 43-69. (Trabalho original publicado em 1951)

As Estrelas Descem à Terra. São Paulo: Editora da UNESP, 2008 (Trabalho originalmente publicado em 1953).

. Educação após Auschwitz. In: Educação e. Emancipação. São Paulo: Paz e Terra, 1995. (Trabalho original publicado em 1955) 
. Sobre a relação entre sociologia e psicologia. In: Ensaios sobre psicologia social e psicanálise. São Paulo: Editora Unesp, 2015, 71-135. (Trabalho original publicado em 1955)

Teoria freudiana e o padrão da propaganda fascista.In: Ensaios sobre psicologia social e psicanálise. São Paulo: Editora Unesp, 2015, 137-152. (Trabalho original publicado em 1951)

ADORNO, T. W.; HORKHEIMER, M . A indústria cultural - o esclarecimento como mistificação das massas. In: ADORNO, T. W.; HORKHEIMER, M. Dialética do Esclarecimento: fragmentos filosóficos. Rio de Janeiro: Jorge Zahar Editora, 2011, p. 99-138. (Trabalho originalmente publicado em 1947)

Cultrix, 1978, p.78-91.(Trabalho originalmente publicado em 1956)

. Elementos do antissemitismo. In: ADORNO, T. W.;

HORKHEIMER, M. Dialética do Esclarecimento: fragmentos filosóficos. Rio de Janeiro: Jorge Zahar Editora, 2011, p. 139-172. (Trabalho originalmente publicado em 1947)

. O conceito de esclarecimento. In: ADORNO, T. W.; HORKHEIMER, M. Dialética do Esclarecimento: fragmentos filosóficos. Rio de Janeiro: Jorge Zahar Editora, 2011, p. 19-52. (Trabalho originalmente publicado em 1947)

. O grupo.In: Temas básicos da sociologia. São Paulo:

Cultrix, 1978, p.61-77.(Trabalho originalmente publicado em 1956)

CROCHÍK, J. L.(Org.). Teoria Crítica da Sociedade e Psicologia: alguns ensaios. Araraquara: Junqueira\&Marineditores, 2011.

DAHMER. H. Adorno's view of psychoanalysis. ThesisEleven, Australia.V.111(1), 97-109.

FREITAS, V. Adorno e Horkheimer leitores de Freud. Remate de Males,Campinas-SP, (30.1):. 123-146, 2010.

FREUD, S.O inquietante. In: Sigmund Freud: obras completas (vol.14) (P. de Souza, Trad.). São Paulo, Companhia das Letras, 328-376, 2010. (Trabalho original publicado em 1919)

Psicologia das massas e análise do eu.In: Sigmund Freud: obras completas (vol.15) (P. de Souza, Trad.). São Paulo, Companhia das Letras, 13-113, 2011. (Trabalho original publicado em 1921)

. Totem e Tabu. In: Sigmund Freud: obras completas (vol.11) (P. de Souza, Trad.). São Paulo, Companhia das Letras, 2013. (Trabalho original publicado em 1913)

JAY, M. A Imaginação Dialética: história da Escola de Frankfurt e do Instituto de Pesquisas Sociais (1923-1950). Rio de Janeiro: Contraponto Editora, 2008. 
JACOBY, R. Social Amnesia: A critique ofcontemporarypsychology, from Adler toLaing. Boston: Beacon Press, 1975.

LE BON, G. PsychologiedesFoules.5 ${ }^{\text {a }}$ Ed. Paris: PUF, 1995. (Trabalho originalmente publicado em 1885)

McDOUGALL, W. The Group Mind. Cambridge: Cambridge University Press, 1973. (Trabalho originalmente publicado em 1920)

ROBERTS, J. A dialética do esclarecimento.In: RUSH, Fred (Org). Teoria Crítica. Aparecida: Idéias\& Letras, 2008, p. 85-104.

SLOTERDIJK, P.O Desprezo das Massas: ensaio sobre lutas culturais na sociedade moderna. São Paulo, Estação Liberdade, 2002.

TARDE, G. Les Lois de L'imitation. Paris: Kimé, 1993. (Trabalho originalmente publicado em 1888)

TROTTER, W. Instincts of the Herd in Peace and War. Nova Iorque, MacMillan,1953. (Trabalho originalmente publicado em 1919)

WHITEBOOK, J. A união de Marx e Freud: a Teoria Crítica e a Psicanálise. In: RUSH, Fred (Org). Teoria Crítica. Aparecida: Idéias\& Letras, 2008, p. 107-117.

WIGGERSHAUS, R. A Escola de Frankfurt: história, desenvolvimento teórico, significação política. Rio de Janeiro: DIFEL, 2002.

ZIZEK, S. Eles não sabem o que fazem: o sublime objeto da ideologia. Rio de Janeiro: Jorge Zahar Editor, 1992. 